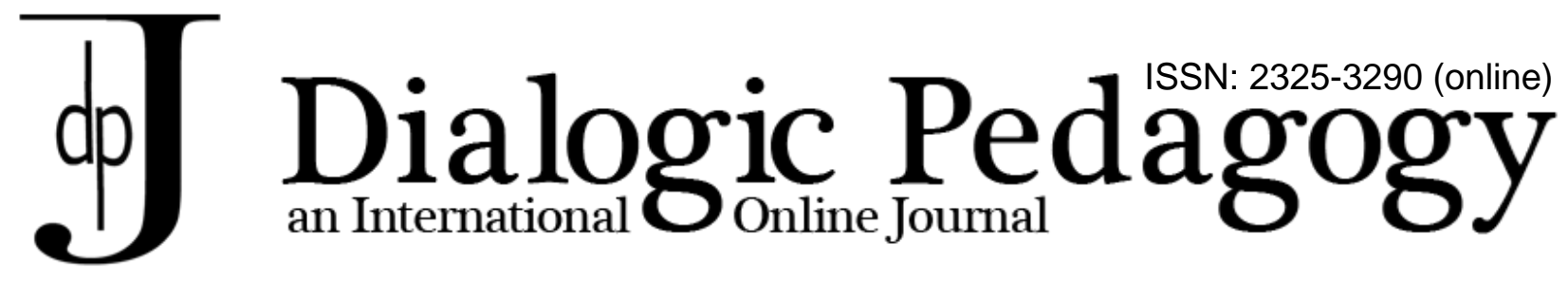

\title{
DPJ Editorial: Launching the new journal
}
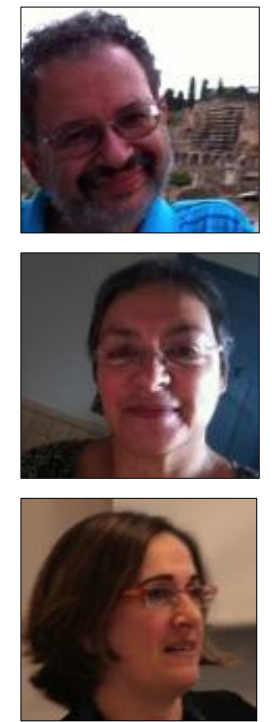

Eugene Matusov

DPJ Editor-in-Chief

University of Delaware, USA

Ana Marjanovic-Shane

DPJ Deputy Editor-in-Chief

Chestnut Hill College, USA

Yifat Ben-David Kolikant

DPJ Deputy Editor-in-Chief

Hebrew University, Israel

/This Editorial is not necessary the voice of the journal but the voices of the particular DPJ editors at the given moment/

\section{Welcome: Why do we need another journal?}

Dear Reader, welcome to "Dialogic Pedagogy: An International On-line Journal" (DPJ)! We are happy to announce a new academic Open Access online polyphonic journal dedicated to the interdisciplinary field of Dialogic Pedagogy.

You may ask, "Why to have another journal? Don't we have enough already?" Indeed, currently many journals appear as mushrooms after a rain and some of them disappear as quickly as they appear because they don't have readership, authorship, reveiwership, or even editorship. This is a good concern that we are going to address below.

We have started DPJ for several reasons. One is that there are no journals dedicated to "Dialogic Pedagogy" (or "Dialogic Teaching" or "Dialogic Learning" or "Dialogic Education" or "Dialogue and Education"). At the same time, in our view, Dialogic Pedagogy cannot be reduced to any other existing educational approach (or method, or strategy, or educational philosophy).

Second, we had a hunger for a place for a vivid discussion, for learning with, from, and against our peers. We envision this journal as such a forum. In this journal we intend to "do as we preach", 
namely the review and decision making processes will be dialogical. Two of us, Eugene Matusov and Ana Marjanovic-Shane, how to say it politely, have been sick and tired of rather unwelcoming practices that we have experienced in many other academic journals and conferences focusing on creating "similarminded clubs and circles," in which agreement is proxy for academic quality and even the truth. For Ana and Eugene, this was a third reason to start this journal. The third editor, Yifat Ben-David Kolikant does not share this emotional state. Thus, the three of us thought -though for different reasons --that the journal should be a dialogical venue to discuss dialogicality. We also say on this outset that we intend want to embrace disagreement and controversy. We believe it is an important engine for learning and scholarship.

\section{So, "Will this journal be for you?" What is Dialogic Pedagogy and who belongs to the DPJ international community}

The terms like "dialogue" and "dialogic" are heard a lot in the education arena. They encompass a variety of meanings. Some educationalists may say that Dialogic Pedagogy is about using interaction in a classroom rather than lecturing students. Others may say that using some kind natural conversation in the classroom over contrived known-answer questions is Dialogic Pedagogy (e.g., "Instructional Conversation"). Some others may say that Dialogic Pedagogy is a Socratic method of challenging students' misconceptional opinions, attitudes, and worldviews. In contrast, some other people think that Dialogic Pedagogy is an educational philosophy rather than a method, strategy, or a tool that can be switched on and off, involving meaning making process, relating to other people, and certain way of being in the world.

In another divide about domain, some educationalists interested in Dialogic Pedagogy may focus more on teacher's teaching, some on students' learning, some on students' self-studies, some on educational environment outside of schooling, and yet some on conditions that canalize education to shape it in one way over another.

Educators may differ about promises of Dialogic Pedagogy. Some educators passionately argue that Dialogic Pedagogy is the pathway and the tool for social justice, equity, democratic participation, and critical thinking. While others focus on rationality, search for truth, and intellectual rigor that Dialogic Pedagogy promises. Some may be interested in using Dialogic Pedagogy for making students deeper understand the academic curriculum while others may be more interested in promoting students' agency and activism in targeted practices.

Finally, some people may criticize Dialogic Pedagogy all together as being unrealistic, culturally biased, ineffective, educationally misleading, limited, and so on.

In our view, all of these educationalists belong to the DPJ community and are very welcomed to participate in the journal. Whoever has found any relevance in the notion of "Dialogic Pedagogy" (and synonymous terms and concepts) in their attraction or repellence to it is welcomed. Those who are indifferent may pass by.

\section{Dialogic nature of DPJ, its governance, and its processes}

A Reader may be surprised, "Why is that? Why can't you define what is 'Dialogic Pedagogy'? Why is it so loose? Why do you want to invite a cacophony of voices? Don't you, yourself, have a vision for Dialogic Pedagogy? Aren't you afraid of losing a focus for a journal that invites everybody but stands for nobody?" Yes, we agree that it can be risky as centrifugal forces can tear the journal apart. However, 
we do not see an alternative because dialogue always starts with diversity, heterogeneity, dissonance, dissent, and, yes, with disagreement. In contrast to many mainstream academic journals, conferences, and societies, we believe that it is dialogue, and not agreement, that is a proxy for truth or academic quality. Truth does not have internal territory but lives on a boundary. Truth lives not in statements but on boundaries of statements of tension, pronounced by different people with diverse, and at times incompatible, ideas and positions. Thus, the definition of what is Dialogic Pedagogy lives in the DP community (in a broader sense) as whole, in its dialogue, and does not belong to anyone who can authoritatively talk on its behalf. Yes, we have our own visions of Dialogic Pedagogy but they make sense only in dialogue with other people having different visions than ours.

That is why we believe in democratic, polyphonic, and dialogic government of our journal. We think that everyone who wants to be a DPJ editor can and should join the DPJ editorial board. The DPJ editorial board is actively involved in strategic decision making about the journal. Currently, it has about 100 volunteers with diverse and dynamic levels of activism and participation, which is OK and how it should be, in our view. The decision making process is democratic, participatory, and dialogic. We discuss issues first and then vote on them. Any member of the DPJ Editorial Board can offer an agenda for discussion and voting.

\section{History of the development of the journal}

The DPJ has started in 2010 when Mark Smith and Eugene Matusov started exploring how to develop an alternative Open Access Online journal on dialogic pedagogy. The focus on Open Access and Online has come from a concern that we need to make academia more accessible, open, reaching out and reaching further internationally, democratic, and free from for-profit businesses of publishers as much as possible. In the summer 2010, Eugene Matusov has launched a website on Dialogic Pedagogy that included the proposal for the journal. By now several similar sites have been started: The School of the Dialogue of Cultures (in Russian, by followers of a Russian/Soviet philosopher Vladimir Bibler, -probably, the oldest website on Dialogic Pedagogy), Dialogic Teaching (by Robin Alexander), Dialogic Learning (Wikipedia), Dialogic Education for the Internet Age (by Rupert Wegerif).

Our next impetus has come from the mini-Bakhtinian conference on Dialogic Pedagogy, Delaware, USA, in March-April 2012, where many participants (e.g., Ana Marjanovic-Shane, Yifat BenDavid Kolikant, Jayne White) called for establishment of a new journal on Dialogic Pedagogy. One concern that some participants had was whether the new journal would have enough readers, authors, reviewers, and editors. To address this issue Ana (Marjanovic-Shane) and Eugene (Matusov) launched an international survey about a potential interest in a new journal in the mid April 2012 for 2 months. We sent about 1000 emails. 278 people from 36 countries have responded. Out of them 180 people want to serve as reviewers and 113 people plan to be authors.

In June 2012, we, Ana and Eugene, launched a Google forum group of the DPJ Editorial Board discussing and making decisions about the organization and policies of the new journal (you can find the results of this decision making process here). At the end of June 2012, we engaged in a fundraising campaign (with a goal of raising \$2000) and negotiations with several University Libraries about publishing and hosting our Open Access Online journal. At the end of July, the DPJ Editorial Board elected its first Officers. By the end of July, we raised \$2,789 (yes! - it's incredible, thanks!). On September $1^{\text {st }} 2012$, we signed a contract with the University of Pittsburgh Digital Library for publishing and hosting our journal. Our remaining step is to incorporate the journal. 
Instead of establishing a journal around an existing society, we have decided to build a society around a new journal. Let's see if this model works!

\section{The past, present and future in the society and DP/Education}

We live in interesting times! Almost everywhere we see several trends in the society across the globe affecting education that sometimes support and sometime fight with each other (let's see if you and how you would disagree ;-). One big trend - a more dialogic trend -- is increasing contact among diverse people, ideas, cultures, values, worldviews, perceptions, social groups, and desires through Internet, social networking, commerce, economy, professional organizations, technology, art, entertainment, science, and political actions. There seems to be growing tolerance to this diversity and even appreciation of it. We also see is increasing demand, appreciation, desire, and need for human creativity, agency, design, eventfulness, postupok (i.e., in Russian "ethical deed"), uniqueness, authorship, meaningfulness, irreplaceability, immeasurability, particularism, embodiment, and responsibility in economy, politics, design, and definition of "good life".

At the same time, there is an opposite, and more monologic, trend coming from a strong opposition if not fight of this diversity through the religious, ideological, patriarchal, and nationalist fundamentalism, the bureaucratic standardization, the cultural assimilation, and the accountability "quality control". In addition and, arguably, concord with it, there is also an increasing focus on measurement (especially, summative assessment but not only), metrics, accountability, automatization, robotization, certainty, compliance, replaceability, conformity, predictability, finalizing, universalism, decontextualization, alienation, reification, and disembodiment - all in support of conventional education.

In our view, these two societal trends - dialogic and monologic -- are opposing and irreconcilable (in contrast to some of Dialogic Pedagogy colleagues of ours). These opposing trends have very different and, we strongly argue, antithetical visions for education. According to one type of the trends, education is defined by moving the students' consciousness to the curricular endpoints preset by the society (and/or educators) - Aristotle called this type of practice poiésis (поі́ббı). According to the other type of the trends, education is defined by developing new meanings, new qualities, new values that have not been

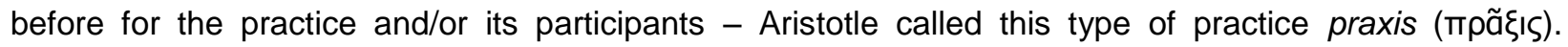
Although we, personally, can be wrong, we think that Dialogic Pedagogy belongs to the second definition of education - this is our particular, partisan position, of course. Historically and currently, education is overwhelmingly defined as poiésis. However, we think that the future is after the praxis definition of education.

We see these opposing societal visions as defining the current moment of education, and as the key forces that determine almost every aspect of educational practice, its potentials and its limits. We invite you, reader, and all DPJ community to explore these and other important and interesting issues in our journal.

\section{What major challenges do we, DPJ Editors, see in and for the field of Dialogic Pedagogy?}

Here is our particular and parochial list of important tensions in and for the field of Dialogic Pedagogy:

- What is Dialogue? Why is it important for Education and elsewhere? Is dialogue for raising test scores in school? Is it about having social interaction in the classroom? Is it about learning better and deeper 
standardized curriculum? Is it about challenging students' misconceptions? Is it about searching for truth? Is dialogue for the students to achieve rationality and objectivity? Is dialogue about humanity of human relations? Is it about giving students' their voice and promoting their agency? Is it about a meaning making process? Is it about testing ideas? Something else? Are these possible pedagogical goals and functions compatible or incompatible with each other (some, all, which ones)? Are some of them undesirable? If so, which ones and why?

- What is Dialogic Pedagogy? Is Dialogic Pedagogy some kind of teaching method aimed at the teaching efficiency or is it a philosophical, value-based, approach? Why Dialogic Pedagogy? What is Dialogic Learning? Dialogic Teaching? Dialogic Educational Chronotope?

- What is the overall principle of Dialogic Pedagogy: search for truth, or promotion of social justice, or establishment of social peace and stability, or non-violence, or tolerance to the other, or rationality, or objectivity, or humanity, or production of knowledge, or deep learning, or authorship, or effective instruction? Do we need the overarching principle in Dialogic Pedagogy? What should we, Dialogic Educators, do when these priorities are in conflict with each other?

- What are voice, agency, polyphony, and authorship in Dialogic Pedagogy? Why are these concepts important for Dialogic Pedagogy? Are they? What is Bakhtin's notion of "consciousnesses with equal rights" in the context of Dialogic Pedagogy (e.g., the relationship between the teacher and the student)? Can consciousnesses be transparent to each other in principle (i.e., can people fully understand each other)? If not, what are the implications for education? Can the teacher be in genuine dialogue, interested in discussed ideas, with the student when the teacher knows more than the student? Is pedagogical dialogue possible?

- Can Dialogic Pedagogy and Conventional Institutional Pedagogical Practices somewhat comfortably live together? Can Dialogic Pedagogy fit Conventional Educational Chronotope or not? If not why not? If so, how and under what conditions?

- What is role, if any, of teacher's unilateral, non-negotiable, impositions on students, demanding them to engage in certain learning activities, so common in conventional monologic pedagogy, in Dialogic Pedagogy?

- What is Dialogic Pedagogy Scholarship? Should it be solely based on rationalist objectivist necessity-based Internally Persuasive Discourse (IPD)? Or should it also involve some other forms of Internally Persuasive Discourses, like, for example, Authorial, Phrônēsis-based (i.e., practical, situated wisdom), Sophia-based (i.e., evaluation of goodness, values, and desires)?

- What is Dialogic Pedagogy Empirical Research? Should it be methodology-based as in exact, natural sciences, in which the quality of research is decided by a method used, -- method that pre-exist a particular research, its material and goals? Or should it be anti-methodological, in which a way of researching is grounded in the material and emerging goals and research questions and its quality is defined by a dialogue in an Internally Persuasive Discourse (but not necessarily exclusively rationalist IPD)?

- What are diverse forms of Dialogic Educational authorship by learners and how to promote them? Can these forms of Dialogic Educational authorship be in conflict with each other? If so, how to manage these conflicts?

- What are limitations and biases of Dialogic Pedagogy Education and even Education per se? Is Education universally good for all, all places, all times, and all circumstances? What is the limit of Education in itself: when must Education stop and Politics, and/or Law, and/or Technology, and/or Medicine, and/or Division of Labor begin to address certain personal and societal problems? How to address these limitations? Is 
Dialogic Pedagogy biased and limited: culturally, socio-economically, communicationally (verbally), by age of the participants, emotionally, by the academic subject, politically, by the level of acuteness of political conflict or oppression the participants are engaged, by cognitive ability, by the degree of (un)familiarity of the material, by gender, etc.? If so, why, in what ways, and how to address it? If not, why not?

- What is the relationship of Dialogic Pedagogy and instructional and interactional formats? For example, can lecture be dialogic? Can instructional conversation be monologic? Are all information seeking question dialogic? Are all information-known questions monologic?

- $\quad$ Can learning be measured from Dialogic Pedagogy view? Why should it be measured? If learning cannot be measured, how can and should we deal with immeasurable important concepts in Dialogic Pedagogy practice and scholarship?

- How should the quality of Education be defined in Dialogic Pedagogy? Is it through accountability, as it is in Conventional Pedagogy? Is it through answerability, as it is in Conventional Pedagogy? (How is answerability different from accountability?) Is it through self-correcting processes (i.e., negotiable through ethical acts), if so, what are they and how to design-launch them? Does the issue of the quality of Education in Dialogic Pedagogy have to be in itself a part of education, engaging students/learners in critical dialogue about what good education is for them? Other dialogic alternatives?

- What are economic, social, technological, and political costs of Dialogic Pedagogy? How can we address the issues of Dialogic Pedagogy's costs?

- What is the relationship between Dialogic Pedagogy and non-Dialogic Pedagogy practices from the Dialogic Pedagogy point of view? Should Dialogic Pedagogy impose itself on all institutions, educators, learners, families, and communities who may oppose Dialogic Pedagogy? If not, what the relationship to the Educational Other should be?

We hope this list is a good invitation for us to start our professional discourse on Dialogic Pedagogy. Feel free, however, to bring your important tensions, dilemma, and agendas that may be not on our list.

\section{Call for participation in DPJ}

So, is this new journal for you or not, Dear Reader? It is for you to decide, of course. But if you decide positively, let us list possible diverse participations that are currently available in the DPJ.

First, you can be a casual or systematic reader. For that you do not need to do anything, except making a bookmark of the journal on your browser.

Second, you may want to provide your comments on published articles or even discuss submitted manuscripts or participate in forums. For that you need to register (free of charge, of course). You will also receive notifications and announcements about new publications, submissions, conferences and so on.

Third, you can become an author and submit a manuscript for a DPJ publication. Your manuscript will go to reviewers and will be posted on the DPJ community space only available for the registered DPJ community members. You can choose to be anonymous or attributed for the reviewing process. You can also participate in discussion of your own manuscript online. For that, of course, you need to register and submit a manuscript. 
Fourth, you may want to serve as a reviewer. For that you need to register and indicate in your profile this service.

Fifth, finally, you can become a member of the DPJ Editorial Board. Members of the Editorial Board are engaged in strategic decision making and will constitute a pool of Managing Editors who will be assigned submitted manuscript. For that you need to register and send us an email with your intent linked on the DPJ front splash page.

We hope that you will find participation in Dialogic Pedagogy journal and DPJ community exciting, productive, inspiring, and enjoyable experiences. See you on the DPJ website!

We want to thank and congratulate all of those who have been contributing in the establishment of the journal and encourage new members to join the process!

\section{Information about the authors:}

Eugene Matusov, Ph.D. Editor-in-Chief is a Professor of Education at the University of Delaware, USA. He was born in the Soviet Union. He studied developmental psychology with Soviet researchers working in the Vygotskian paradigm and worked as a schoolteacher before immigrating to the United States. He uses sociocultural and Bakhtinian dialogic approaches to education. Email: ematusov@udel.edu

Ana Marjanovic-Shane, Ph.D. Deputy Editor-in-Chief is an Assistant Professor of Education at Chestnut Hill College, Philadelphia, PA, USA. Before immigrating to the USA she worked as a researcher in the Institute for Educational Research in Belgrade, Yugoslavia using the socio-cultural approach to study meaning making and creativity in education. She uses a Bakhtinian orientation to understand the dynamics of play and educational events. Email: anamshane@gmail.com.

Yifat Ben-David Kolikant, Ph.D. Deputy Editor-in-Chief is an associate professor in the School of Education, Hebrew University of Jerusalem, Israel. Her research interests are the inter-relations among technology, schooling, and learning and the characterization of effective educational environments in an age of globalization and rapid changes. Email: yifat.kolikant@mail.huji.ac.il

\section{(cc) EY}

Articles in this journal are licensed under a Creative Commons Attribution 3.0 United States License.

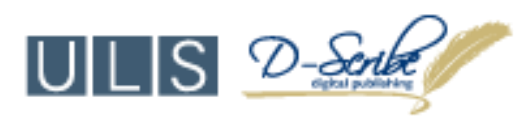

This journal is published by the University Library System, University of Pittsburgh as part of its D-Scribe Digital Publishing Program and is cosponsored by the University of Pittsburgh Press. 